\title{
DELIMITACIÓN \\ DE LA COMPETENCIA \\ AUTONÓMICA PARA \\ LA REGULACIÓN \\ DE LOS DERECHOS \\ FUNDAMENTALES
}

ENRIQUE LUCAS MURILLO DE LA CUEVA

Profesor Titular de Derecho Constitucional

Universidad del País Vasco

Euskal Herriko Unibertsitatea 



\title{
DELIMITACIÓN DE LA COMPETENCIA AUTONÓMICA PARA LA REGULACIÓN DE LOS DERECHOS FUNDAMENTALES
}

POR

\author{
ENRIQUE LUCAS MURILLO DE LA CUEVA \\ Profesor Titular de Derecho Constitucional \\ Universidad del País Vasco \\ Euskal Herriko Unibertsitatea
}

\section{INTRODUCCIÓN'}

La Constitución de 1978 se encuentra entre las más avanzadas en el reconocimiento y protección de los derechos y libertades. Su artículo 10.1 dice que son inviolables e inherentes a la dignidad de la persona y, en cuanto tales, los califica de fundamento del orden político y la paz social.

Ese carácter fundamentador del propio sistema constitucional es coherente con la definición de España como Estado social y democrático de Derecho y con la proclamación de los valores superiores del or-

1 Este trabajo es resumen de uno de los capítulos de la obra Cláusulas de igualdad y autonomía política, que será publicado próximamente por Civitas en coedición con el IVAP. 
denamiento jurídico que realiza el artículo 1:1 CE. Pero, más allá de las fórmulas y de la solemnidad de los enunciados de los preceptos citados, el constituyente se ha preocupado de establecer un completo conjunto de mandatos y de garantías que dan a los derechos fundamentales un carácter vinculante para todos los poderes públicos, incluidos los legislativos; ha reservado a la ley orgánica el desarrollo directo de ese grupo de derechos y les ha dado una fuerte protección basada en mecanismos jurisdiccionales y en el amparo ante el Tribunal Constitucional. Asimismo, ha creado la institución del Defensor del Pueblo y ha incluido al repetido grupo de derechos dentro de las materias que gozan de la cuasi intangibilidad que proporciona el artículo $168 \mathrm{CE}$ a efectos de revisión constitucional.

La importancia de los derechos fundamentales ha sido tenida en cuenta, también, por el constituyente a la hora de diseñar la organización de los poderes, tanto en lo que se refiere a la llamada división horizontal, como a la vertical o territorial de los mismos. Con relación a esta última, el Título VIII (artículo 139 CE) contiene un principio que ha de orientar la acción de las Comunidades Autónomas para que el ejercicio de sus competencias no ponga en riesgo ni quiebre el derecho a la igualdad de todos los españoles por razón del lugar en donde tengan fijada su residencia. Por su parte, el artículo $149.1 \mathrm{CE}$, además de reservar en exclusiva al Estado las competencias que más directamente afectan a la libertad y a la tutela judicial de los derechos, le confía la regulación de las condiciones básicas que garanticen la igualdad de todos los españoles en el ejercicio de sus derechos y en el cumplimiento de sus deberes constitucionales. Algunos de tales derechos y deberes han sido objeto de reparto competencial entre el Estado y las Comunidades Autónomas conforme a las reglas establecidas en el texto constitucional.

Tan imponente panoplia de instrumentos al servicio de los derechos fundamentales es por sí misma suficiente para dar respuesta adecuada a las exigencias que derivan del artículo 10.1 CE. De ese modo, los citados derechos vinculan y se encuentran protegidos por igual con independencia de cuál sea el poder público que actúe sobre ellos. Lo mismo da que se trate de órganos estatales o autonómicos. Sin embargo, la complejidad del sistema de fuentes del Derecho que establece la Constitución, acentuada por la de las normas sobre distribución de competencias, ha dificultado la correcta interpretación acerca de la forma en que han de articularse las leyes orgánicas que deben desarrollar los derechos incluidos en su ámbito de reserva y las leyes ordinarias que regulan su ejercicio, que serán estatales o autonómicas en función de dichas normas de distribución competencial. 
Las dificultades interpretativas han llevado a considerar a algunos que, al margen de lo que dijeran las previsiones específicas sobre el reparto de competencias, de la reserva de ley orgánica, de la cláusula del artículo 149.1.1. $\mathrm{CE}$ y del principio de igualdad del artículo 139 $\mathrm{CE}$, se podría deducir una suerte de atribución general de las competencias sobre derechos fundamentales al Estado. Un título universal que se impondría a las normas de los estatutos de autonomía sobre esos derechos.

\section{LOS PRINCIPIOS DE IGUALDAD Y DE AUTONOMÍA}

El énfasis en la dimensión garantista de los derechos fundamentales que se constata en la Constitución de 1978 está orientado al establecimiento de un estatuto constitucional de la libertad. Los mandatos de actuación y promoción que dirige a los poderes públicos (artículo 9.2 CE, principalmente) pretenden, a su vez, lograr un estatuto constitucional de la igualdad ${ }^{2}$.

En efecto, la Constitución no se limita a crear los instrumentos $y$ mecanismos que protegen a los individuos y a los grupos frente a las agresiones o intromisiones de los poderes públicos en su esfera de libertad. La norma fundamental, además de prestar esa garantía de raíz liberal, también impone a dichos poderes deberes de actuación para lograr la realización y efectividad de los derechos. Ya sean de los llamados de libertad, ya sean económicos y sociales. Con respecto a estos

2 Sobre las dificultades para adecuar la concepción liberal de los derechos fundamentales a la realidad del Estado social ver DE VEGA, P., "La crisis de los derechos fundamentales", en A.A.V.V., Derecho y Economia en el Estado social, Tecnos 1988, pp. 124 y 125. Ver, también Fioravanti, M., Los derechos fundamentales. Apuntes de historia de las Constituciones, ed. Trotta, Madrid 1996, p. 130. Dice este autor que con la Constitución como norma de garantía renace la idea de que la validez de las normas del Estado puede $y$ debe ser juzgada partiendo de una norma fundamental que precede a la autoridad misma del Estado. $Y$ con la Constitución como norma directiva fundamental renace la idea -originariamente de impronta contractualista, pero revisada ahora a la luz de una realidad constitucional distinta que prevé la presencia de fuerzas organizadas como los partidos politicos- de que el mismo Estado existe solo como el resultado de un encuentro de voluntades, como consecuencia de una dirección elegida, que los poderes públicos han de perseguir de común acuerdo. La conexión entre los derechos sociales y las cláusulas generales del principio de igualdad han sido explicadas por FreIXES SAN JUAN, T., Los derechos sociales de los trabajadores en la Constitución. Ministerio de Trabajo y Seguridad Social, Madrid 1986, pp. 349 y ss. 
últimos, el Capítulo III fija unos principios rectores de la politica social y económica que definen las misiones que se encomiendan al Estado ( $y$, como parte de él, a las Comunidades Autónomas). Esos principios se han de perseguir constantemente a través del ejercicio de todas sus funciones pues, de acuerdo con el artículo 53.3 CE, informarán la legislación positiva, la práctica judicial y la actuación de los poderes públicos. Las leyes que los desarrollen pueden en cumplimiento de ese mandato, traducir algunos de esos principios en auténticos derechos subjetivos y garantizarlos jurisdiccionalmente (artículo 53.3 CE).

Ha de insistirse en que los deberes positivos que se señalan al legislador (y a los demás poderes públicos) alcanzan también a los derechos del Capítulo II, unos derechos cuya estructura no permite su definición como "libertades negativas" que reclaman la abstención del Estado, pues entre ese grupo de derechos se encuentran algunos que, como ha puesto en evidencia PACE, demandan, asimismo, su acción e, incluso, determinadas prestaciones de naturaleza diversa ${ }^{3}$. Sobre esos derechos actúa igualmente la cláusula transformadora de la Constitución (artículo 9.2 CE) y, todos, con independencia del Capítulo en el que se hallen, están directamente conectados con los valores superiores del ordenamiento jurídico (artículo 1.1 CE) ya que integran, sin excepción, esa estructura o fundamento del orden jurídico del que habla el artículo 10.1 CE.

Cuanto decimos cuadra con un Estado social y democrático de Derecho, fórmula que no ha de entenderse como la simple yuxtaposi-

3 Según este autor, la figura de la pretensión para distinguir el contenido de los derechos de libertad no resulta satisfactoria ya que la razón de su reconocimiento no está en la abstención del Estado, sino en la valoración favorable que merece el interés individual en ejercer todas aquellas facultades que constituyen el contenido de los diferentes derechos de libertad. De ahi, la impropiedad conceptual de la expresión "libertad negativa"; una expresión que continúa presuponiendo un Estado "omnipotente y soberano" y un escenario normativo todavía "estadocéntrico». En segundo lugar, la figura de la "pretensión" se basaba en una relación bilateral (ciudadano-Estado), propia de la teoría de la autolimitación del poder estatal, que no resulta adecuada cuando lo que se predica es la eficacia erga omnes de los derechos fundamentales en el marco de un sistema en el que los derechos son interdependientes entre si. Finalmente, como consecuencia de lo anterior, las normas legislativas han de asumir una función de limitación de derechos de libertad para que su ejercicio por unas personas no implique la vulneración de los mismos derechos por otras que entran en relación con las primeras. PACE, A., "La heterogénea estructura de los derechos fundamentales", en Cuadernos de Derecho Público, n. 3 enero-abril 1998, pp. 20 y 21 . Ver, asimismo, FreIXES SAN JUAN, T., Constitución y derechos fundamentales: I-Estructura jurídica y función constitucional de los derechos. Promociones y Publicaciones Universitarias, Barcelona 1992. 
ción de la garantía de la libertad en la que se basa el Estado de Derecho, el intervencionismo estatal que caracteriza al Estado social y la legitimación a través de la participación y la representación que implica el Estado democrático. Se trata más bien de la integración de esas tres dimensiones y del equilibrio entre ellas.

Así, la Constitución persigue la plena realización de los derechos de acuerdo con el significado y función que cada uno de ellos tiene en el momento y en el espacio en el que se inserta el propio texto fundamen$\mathrm{tal}^{4}$. Ahora bien, cuando reconoce cada derecho, define su contenido, lo declara vinculante para los poderes públicos y determina sus garantías específicas, no siempre perfila definitivamente todos los contornos del derecho ni, tampoco, impone siempre, la aludida vinculación en términos negativos o prohibitivos sino que, también, habilita su regulación por el legislador ${ }^{5}$. La habilitación se explica porque los derechos fundamentales, que además de su carácter subjetivo tienen una dimensión institucional, son mutables en función del desarrollo económico, social y cultural. De ahí que sea necesario en muchas ocasiones que la norma constitucional se abra, de acuerdo con el principio democrático, a la concreción ulterior por parte del legislador a través de ese proceso de libre discusión pública que supone el procedimiento legislativo ${ }^{6}$.

En nuestro caso, la Constitución ha querido que la concreción de sus preceptos sobre derechos fundamentales y libertades públicas se

4 Hesse, K. Escritos de Derecho Constitucional, selección, traducción e introducción de Cruz VilLaLón, P., C.E.C., 2." ed., Madrid, 1992, pp. 17 y ss.

5 Ver DE OTTO, I. "La regulación de los derechos y libertades", en MARTín-RETORTILLO, L. y DE OTto, I., Derechos fundamentales y Constitución, Civitas, Madrid, 1988 , pp. 103 a 107 , donde pone de relieve la peculiaridad que presenta el artículo 53.1 CE con respecto al 19.2 LFB, pues mientras este último concibe el contenido esencial exclusivamente como límite frente al legislador, nuestro artículo $53.1 \mathrm{CE}$, es también habilitante para el legislador. Como dice CRUz VILLALÓN, P. "Derechos fundamentales y legislación", Estudios de Derecho Público en homenaje a lgnacio de Otto, Universidad de Oviedo 1993, p. 417, en este precepto no se preveria únicamente un supuesto de limitabilidad de un derecho, sino además, si se permite hablar así, el de su "conformabilidad".

6 La citada dimensión ha sido objeto de desarrollo por P. HäBERLE, La libertad Fundamental en el Estado Constitucional, Fondo Editorial de la Pontificia Universidad Católica del Perú, 1997, pp.163 a 254. Su punto de partida está en las tesis de HAURIOU Y KAUFMANN en relación con el doble carácter de los derechos fundamentales: individual o subjetivo e institucional que ya habían diferenciado Rudolf SMEND (Constitución y Derecho Constitucional, CEC, Madrid, 1985, pp.165 y ss.) y Hermann Heller (Teoria del Estado, FCE, México, 1974, pp. 209 y 210). Ver, también, BöcKENFÖRDE, E. W., Escritos sobre Derechos Fundamentales, Nomos Verlagsgsellschaft Baden-Baden, 1993, pp. 53 a 57. 
lleve a cabo interpretándolos de acuerdo con el significado que les hayan dado las normas invocadas en el artículo 10.2 CE y sin afectación de su contenido esencial (artículo 53.1 CE). Una concreción que no ha confiado directamente al legislador ordinario sino que se realiza a partir del desarrollo directo y estricto que de dichos preceptos se haga a través de un procedimiento legislativo especial, como es el que, conforme al artículo 81.2 CE, ha de seguirse para aprobar las leyes orgánicas previstas en el apartado 1 del mismo artículo.

Una vez que se ha delimitado el ámbito abierto a la libre configuración del legislador ordinario, éste, a diferencia de lo que ocurría en el constitucionalismo decimonónico, ya no aparece como señor de los derechos sino como servidor de los mismos. No decide sobre su existencia ni los puede limitar o condicionar más allá de lo que la Constitución y las leyes orgánicas se lo permitan y, cuando lo hace, es para salvaguardar la efectividad del derecho de que se trate por todos sus titulares, pues no hay que olvidar que uel respeto a los derechos de los demás" forma parte de los fundamentos del orden político y la paz social (artículo 10.1 CE). La ley ordinaria cumple asi una función instrumental y equilibradora, está al servicio de los derechos y debe proporcionales lo necesario para que se ejerzan de forma plena y efectiva por todos los ciudadanos. Como dice Häberle, la actividad legislativa ha de ser una uactividad de elaboración y determinación, conforme a la esencia de los derechos fundamentales, del contenido de éstos últimos", pues es una característica del aspecto institucional de los derechos fundamentales que éstos no son "espacios vacíos de Derecho" sino más bien esferas de vida juridicamente constituidas gracias a una pluralidad de conjuntos normativos ${ }^{7}$. Desde ese punto de vista, la cláusula del Estado social, impone al legislador un rol que coadyuva decisivamente, a garantizar el significado institucional de las libertades ${ }^{8}$.

Cuando nos referimos a la ley ordinaria incluimos, por supuesto, a la autonómica de modo que el mencionado rol también incumbe al legislador de las Comunidades Autónomas. Enlazamos, asi, la cuestión con la organización territorial del poder estatal, pues el Estado social y democrático de Derecho es, además, un Estado Autonómico. Insistimos en que esa forma en nada altera el papel de los derechos fundamentales, tanto en lo relativo a su garantía como a los deberes de actuación que reclaman. En principio, la existencia en su seno de una

7 Häberle, P., ob. cit., p. 204.

8 Häberle, P., ob. cit., p. 209. 
pluralidad de ordenamientos $y$, en consecuencia, de la posibilidad de que los diferentes legisladores adopten opciones diversas que se traduzcan en regulaciones distintas, forma parte de la decisión del constituyente de descentralizar el poder del Estado. No obstante, tal decisión ha de ser coherente con el establecimiento del principio de igualdad en cuanto al ejercicio de los derechos fundamentales por todos los españoles con independencia de su lugar de residencia, razón por la cual la Constitución (y los estatutos de autonomia) contiene(n) previsiones explicitas encaminadas a preservar dicho principio.

En realidad, no se trata de resolver un conflicto ya que las diversas facetas del principio de igualdad, en lugar de entrar en contradicción con el principio autonómico, se integran en él. Por eso, no hay razón para incurrir en la simplificación que supone afirmar que éste último ha de sacrificarse en aras de la igualdad. No debe olvidarse que esta última no se concibe en nuestro ordenamiento de modo absoluto o ilimitado. La Constitución de 1978 se inscribe, a mi juicio, entre las que acogen el pluralismo de principios y valores (la igualdad tiene ese doble carácter en virtud de los artículos 1.1, 9.3 in fine y $14 \mathrm{CE}$ ). Un pluralismo que por un lado, persigue la optimización de cada principio y su legitimación a la luz de los valores $y$, por otro, no se basa en un criterio de jerarquización sino de ponderación. Dado que lo característico de los principios (y de los valores) es su capacidad para relativizarse a fin de poder conciliarse recíprocamente eso es lo que ha de hacerse con los principios de igualdad y de autonomía9 . El primero apela a lo esencial, a las posiciones fundamentales, a la igualdad mínima, y no a todos los aspectos de las situaciones que son objeto de comparación. Es decir, es un principio que presupone

9 Ver Zagrebelsky, G., El derecho dúctil. Ley, derechos, justicia. Ed. Trotta. Madrid, 1995, p. 125. La colisión entre principios es explicada por ALEXY, R., Teoría de los derechos fundamentales, CEC, Madrid, 1993. Según este autor, cuando nos encontramos ante dos principios de signo distinto cada uno de ellos limita la posibilidad jurídica del cumplimiento del otro. Esta situación no es solucionada declarando que uno de los principios no es válido eliminándolo del ordenamiento jurídico. Tampoco se soluciona introduciendo una excepción en uno de los principios de forma tal que en todos los casos futuros este principio tenga que ser considerado como una regla satisfecha o no. La solución de la colisión consiste más bien en que, teniendo en cuenta las circunstancias del caso, se establece entre los principios una relación de precedencia condicionada. La determinación de la relación de precedencia condicionada consiste en que, tomando en cuenta el caso, se indican las condiciones bajo las cuales un principio precede a otro. Bajo otras condiciones, la cuestión de la precedencia puede ser solucionada inversamente. En sentido análogo, ver Dworkin, R., Los derechos en serio, Ariel, 1. ${ }^{\text {ed., }}$ 2. $^{\text {a }}$ reimpresión, 1995, pp. 72 y ss. 
siempre un cierto grado de diferenciación, la cual se admite en tanto tenga una base objetiva y razonable. En fin, la igualdad no se equipara a la uniformidad.

Por su parte, el principio autonómico es una dimensión del principio democrático, dado que es la institucionalización de un proceso político a través del cual se define, en el marco constitucional y estatutario, la orientación política de las Comunidades Autónomas en las que, con los municipios y provincias, se organiza territorialmente el Estado (artículo $137 \mathrm{CE}$ ). Supone la elección (en el ámbito de sus competencias) entre diferentes opciones y favorece la diversidad. Pero la libertad de configuración de la que puede hacer uso el legislador autonómico en dicho proceso tampoco es ilimitada ya que está vinculada en los aspectos esenciales por la propia norma constitucional y por las leyes orgánicas que desarrollan los derechos fundamentales. El hecho de que no abarque un ámbito material tan vasto como el que la Constitución ha reservado al Estado y que, además, se vea incidida por las normas de éste en múltiples materias es, por decirlo asi, una cuestión de cantidad no de cualidad.

Es importante resaltar, también, que el lugar donde se establecen los respectivos limites de la igualdad y la autonomía, y el marco para su conciliación, es la propia Constitución. Ella misma es la que precisa su alcance. Como dice Mercé Barceló, «sólo la Constitución como derecho positivo establece que una determinada norma tiene una, más o menos, fuerza igualadora, sólo la Constitución decide qué materias deberán tener un tratamiento unitario, qué materias deberán tener un tratamiento homogéneo y qué materias podrán tener un tratamiento heterogéneo $" 10$. La aclaración es pertinente para descartar la búsqueda de las cláusulas que garantizan la igualdad en otros lugares y para poner coto a la deducción de principios igualadores implicitos en normas de la Constitución cuya finalidad poco o nada tiene que ver con ese pro-

10 BARCELó, M., Derechos $y$ deberes constitucionales en el Estado Autonómico, Cívitas, Madrid, 1991, pp. 35 a 37. Los principios o cláusulas sobre la igualdad de derechos y obligaciones de todos los ciudadanos están consagradas en las Constituciones de los Estados Federales. Desde la Privileges and Inmunities Clause de la Sección Segunda del artículo IV de la Constitución norteamericana de 1787, hasta las previsiones análogas contenidas en la Constitución suiza o la Ley Fundamental de Bonn. Sobre todo ello, ver Pemán Gavin, lgualdad de los ciudadanos y autonomias territoriales, Civitas, Madrid, 1992, pp. 29 y ss.; Baño León, Las Autonomías Territoriales y el principio de uniformidad de condiciones de vida, IEAL, Madrid, pp. 47 y ss. y Tudela Aranda, J., Derechos Constitucionales y Autonomía Política, Cívitas 1994, pp. 49 a 56. 
pósito". No obstante, hay que reconocer, como ya avanzamos en la introducción, que los enunciados normativos empleados en algunos preceptos constitucionales dificultan la interpretación y dan pie a lecturas uniformizadoras que se alejan a nuestro juicio de su verdadero significado. Así lo ponen de manifiesto no sólo la jurisprudencia del Tribunal Constitucional sino, también, los trabajos científicos sobre la cuestión ${ }^{12}$. Con todo, tanto en un ámbito como en el otro, se va imponiendo la interpretación armónica que sugerimos, de suerte, que va asentándose la idea de que el principio de igualdad es plenamente compatible con el principio autonómico y se integra en las reglas de distribución competencial sin alterarlas ni subvertirlas.

Es necesario, por lo tanto, explicar en qué se concreta y cómo funciona el principio de igualdad en el Estado Autonómico y de qué manera actúa el principio democrático en la organización autonómica que establecen la Constitución y los estatutos de autonomia. En la búsqueda de las verdaderas y las falsas cláusulas de la igualdad nos centrándonos en la reserva a ley orgánica del desarrollo de los derechos fundamentales y las libertades públicas ${ }^{13}$.

\section{RESERVA DE LEY ORGÁNICA. FUNCIÓN CONSTITUCIONAL Y DISTRIBUCIÓN DE COMPETENCIAS}

De la reserva a las leyes orgánicas del desarrollo de los derechos fundamentales y las libertades públicas (artículo $81.1 \mathrm{CE}$ ) no se puede extraer la conclusión de que tenga la función de distribuir competencias entre el Estado y las Comunidades Autónomas. El hecho de que ese tipo de leyes sólo puedan ser emanadas por las Cortes, ya que han

" En contra de la idea de que la cláusula del Estado social confiere al Estado una competencia igualadora, TUDELA ARANDA, ob. cit., p. 332, afirma que cuando el constituyente procedió a la redacción del largo listado del artículo 149.1 CE conocía la naturaleza social del Estado y decidió que la realización del mismo se hiciera a través de las reglas de reparto competencial y no a pesar de ellas. Como consecuencia del principio de autonomía es posible, sin embargo, que el grado de desarrollo del Estado social sea diferente en cada Comunidad Autónoma.

12 Ver las monografías citadas en la nota 13.

13 El estudio del mandato de igualdad enunciado en el artículo $139 \mathrm{CE}$ y la competencia para la regulación de las condiciones básicas que garanticen la igualdad de todos los españoles en el ejercicio de los derechos y en el cumplimiento de los deberes constitucionales (artículo 149.1.1. ${ }^{\circ} \mathrm{CE}$ ), lo he realizado en mi trabajo Cláusula de la igualdad y autonomía política que se publicará próximamente por la editorial Civitas en coedición con el IVAP. 
de ser sometidas a la aprobación por mayoria absoluta del Congreso de los Diputados, en una votación final sobre el conjunto del proyecto (artículo 81.2 CE), si bien tiene una enorme relevancia para precisar el contenido de la norma constitucional que queda indisponible para el legislador ordinario, es ajena a la mencionada distribución.

Ciertamente, en la medida que la ley orgánica ocupe más espacio menos margen de actuación quedará para el legislador autonómico (y para el ordinario estatal) y más igual será la regulación del derecho en todo el territorio del Estado. Ahora bien, el hecho de que se produzca esa incidencia no debe confundir las cosas hasta el extremo de pensar que la repetida reserva encierra una regla especial de reparto competencial. Si se admitiera ese argumento también habria que caracterizar la disciplina de la reforma constitucional o la atribución a las Cortes de facultades en relación con la Corona o la formación del Gobierno, por ejemplo, como normas distributivas de competencias. Al fin y al cabo, en esos y en otros muchos casos, la Constitución sólo se refiere a los órganos generales del Estado. Sin embargo, es evidente que la razón de ser de estas previsiones nada tiene que ver con la organización territorial. Su fundamento y su finalidad se sitúan en otro ámbito diferente por más que, en alguno de los ejemplos (la reforma constitucional) puedan acabar incidiendo de forma decisiva en las Comunidades Autónomas e, incluso, suprimirlas.

Sin perjuicio de volver sobre esta cuestión, lo que ahora interesa saber es cuál es la función que la Constitución ha encomendado a la ley orgánica en relación a los derechos fundamentales y las libertades públicas. Una vez realizada la delimitación positiva, cuando sepamos lo que es, estaremos en condiciones de delimitarla negativamente y decir lo que no es.

\section{A) Función de la reserva a la ley orgánica para el desarrollo de los derechos fundamentales y las libertades públicas}

Como es de sobra conocido, la incorporación de las leyes orgánicas al texto constitucional fue objeto de la inmediata critica de la doctrina que puso de relieve la ambigüedad e indeterminación con que la Constitución las habia configurado y los problemas de interpretación que ello implica ${ }^{14}$. Asimismo, el Tribunal Constitucional, como recuer-

14 Garrorena Morales, A., "Acerca de las leyes orgánicas y de su espuria naturaleza jurídica», R.E.P. N. 13,1980, pp. 169 y ss. Ver también la monografía de 
da la STC 173/1998, enseguida advirtió su carácter extraordinario o excepcional (SSTC 76/1983 y 160/1987), ya que la aprobación de este tipo legislativo supone una retención del poder constituyente, en la medida en que «tiene una función de garantía adicional que conduce a reducir su aplicación a las normas que establecen restricciones de esos derechos o libertades o las desarrollan de modo directo, en cuanto regulan aspectos consustanciales a los mismos, excluyendo por tanto aquellas otras que simplemente afectan a elementos no necesarios sin incidir directamente sobre su ámbito y sus límites" (STC 101/1991, fundamento juridico 2). El ejercicio de esa función extraordinaria de «constituyente permanente" se desarrolla a través de un procedimiento igualmente excepcional, que se caracteriza por la «alteración de los mecanismos normales de la democracia, al sujetar a las mayorías simples del futuro a una limitación adicional a la que la Constitución impone, con el consiguiente riesgo cierto de petrificación del ordenamiento" (STC 76/1983).

Por estos motivos, la doctrina propuso, y el Tribunal Constitucional aceptó en gran medida, una interpretación restrictiva del ámbito de la ley orgánica que se concreta principalmente en dos puntos:

- El rechazo de una concepción meramente formal de la misma y

- El estrechamiento máximo de los contornos materiales a ella reservados.

Así, con ciertas dudas iniciales, el Tribunal Constitucional ha ido precisando estos extremos a través de una doctrina que trata de superar las dificultades motivadas por el discutible encaje de este tipo normativo en el sistema de fuentes. A modo de síntesis, expondremos algunos de sus pronunciamientos más señalados:

este mismo autor El lugar de la ley en la Constitución. C.E.C., 1980, pp. 126 a 129. Otros autores han coincidido en esa valoración. Así, PEMÁN GAVIN, J. "Las leyes orgánicas: concepto y posición en el sistema de fuentes del derecho", en MARTiN-RETORTILlo, S. (Coord.), Estudios sobre la Constitución Española. Homenaje al profesor Eduardo García de Enterría, tomo l, "El ordenamiento jurídico», Civitas, Madrid, 1991 , p. 140, afirma que "el reproche que cabe hacer al constituyente en este punto no es tanto la propia existencia de la ley orgánica (...) sino más bien la excesiva amplitud de los supuestos en los que se exige $y$, especialmente, la escasa fortuna habida a la hora de delimitar su ámbito material, cuestión esta que se ha mostrado problemática desde el momento mismo de entrada en vigor de la Constitución". Tampoco Santamaría Pastor, J. A., Fundamentos de Derecho Administrativo, vol. I, Ed. Fundación Ramón Areces, Madrid, 1988, pp. 566 y 567, regatea críticas a la delimitación constitucional de las leyes orgánicas, que califica como un diseño arbitrario e impreciso fruto del capricho y las urgencias políticas del momento. 
Muy tempranamente, la Séntencia de 5/1981, dejó bien claro que "la reserva de ley orgánica no puede interpretarse de forma tal que cualquier materia ajena a dicha reserva por el hecho de estar incluida en una ley orgánica haya de gozar definitivamente del efecto de congelación del rango' " ${ }^{15}$.

- El análisis del ámbito de la reserva prevista en el artículo 81.1 CE a que conduce la concepción material evita una expansión ilegítima de la legislación orgánica. A este respecto, las SSTC 6/1981 y 6/1982, declararon que la referencia del citado precepto al «desarrollo de los derechos fundamentales y de las libertades públicas", tan sólo alcanza a la Sección 1. ${ }^{a}$ del Capítulo Segundo del Título I (excluido el artículo 14) y se circunscribe a los derechos fundamentales en sentido estricto o más precisamente a su "desarrollo directo" ${ }^{16}$. Otras Sentencias, como la ya citada de 5/1981, ya habian limitado el ámbito reservado al «desarrollo estricto de los preceptos constitucionales" que debe "afectar de manera esencial al derecho fundamental». La STC 25/1984, exigiría, así, que, para que se pueda hablar de desarrollo, a los efectos del artículo $81.1 \mathrm{CE}$, el objeto de la misma sea el derecho fundamental como tal, no aspectos, realidades o instituciones que guarden cualquier tipo

15 Según dicha STC: «si es cierto que existen materias reservadas a las leyes orgánicas (artículo $81.1 \mathrm{CE}$ ), también lo es que las leyes orgánicas están reservadas a estas materias y que, por lo tanto, sería disconforme con la Constitución la ley orgánica que invadiese materias reservadas a la ley ordinarian. Este claro rechazo hacia una concepción formal de la ley orgánica, que marca la línea divisoria entre los espacios propios de este tipo de normas y los de las leyes ordinarias, no impidió, sin embargo, al Tribunal Constitucional, admitir la posibilidad de que en una misma ley convivieran "materias orgánicas" con otras "conexas», es decir, excluidas de la reserva del artículo $81.1 \mathrm{CE}$, siempre y cuando se señalara qué preceptos concretos se calificaban de orgánicos y cuáles de ordinarios. La explicación de tal admisión vendría dada por la necesidad de abordar en un sólo instrumento legislativo la disciplina jurídica de una o varias materias íntimamente relacionadas entre sí, de suerte que la principal atraería hacia sí a las accesorias. El principio de seguridad jurídica quedaría a salvo, no obstante, con la expresión de los artículos que se consideraran orgánicos por la misma ley, correspondiendo al Tribunal Constitucional depurar el exceso o la cortedad de la misma.

16 Sobre las diferentes posturas mantenidas por la doctrina en torno al alcance de la citada expresión del artículo $81.1 \mathrm{CE}$ y la jurisprudencia del Tribunal Constitucional al respecto, ver Chofre SIRVENT, J. Significado y función de las leyes orgánicas, Tecnos, Madrid, 1994, pp. 107 y ss. Sobre el concepto de derechos fundamentales en la Constitución de 1978, ver MARTí-RETORTILLO, L. "Régimen constitucional de los derechos fundamentales", en Martin-Retortillo, L. y De Otro, I., Derechos fundamentales y Constitución, Civitas, Madrid, 1988, pp. 19 a 87. Ver, asimismo, СHOFRE SIRVENT, J., Significado y función..., ob. cit. pp. 126 y ss. 
de relación con su ejercicio 17 . Con gran precisión, en la línea marcada por la STC 5/1981 ${ }^{18}$, la STC $127 / 1994$ (fundamento juridico 3 b) ha afirmado que requiere ley orgánica únicamente la regulación de un derecho fundamental o libertad pública que udesarrolle la Constitución de manera directa y en elementos esenciales para la definición del ejercicio del derecho fundamental, ya sea en una regulación directa, general y global del mismo o en una parcial o sectorial, pero igualmente, relativa a aspectos esenciales del derecho $y$ no, por parcial, menos directa o encaminada a contribuir a la delimitación y definición legal del derecho" (los subrayados son míos).

La ley orgánica es, por tanto, según la STC 173/1998, «el instrumento que tiene por misión el desarrollo normativo inmediato de la Constitución en aquellos aspectos básicos o fundamentales del orden constitucional que por ser complemento indispensable o necesario de la obra del constituyente se sustraen al sistema habitual de mayorías parlamentarias simples ${ }^{19}$. De lo que se deduce, que la ley orgánica sólo se justifica en tanto en cuanto la Constitución requiera tal complemento indispensable $y$ sólo entonces.

La interpretación restrictiva del artículo $81 \mathrm{CE}$ se ve reforzada por la lectura que la doctrina y la jurisprudencia constitucional han hecho del artículo 53.1 CE a fin de no vaciarlo de contenido. Así, como señalara De Otto, ambos preceptos se ocupan de cosas distintas. El primero (artículo 81.1 CE), se refiere al desarrollo de los artículos comprendi-

17 DE OTTO, I. "Los derechos fundamentales y la potestad normativa de las Comunidades Autónomas", R.V.A.P. N. ${ }^{\circ} 10$, Volumen II, 1984, pp. 66 y ss.; Derecho Constitucional. Sistema de fuentes. Ariel Derecho. Barcelona, 1987, pp. 166 a 169, precisó con acierto que el artículo $81.1 \mathrm{CE}$ no posibilita el desarrollo por ley orgánica del concreto derecho fundamental de que se trate, sino el del precepto constitucional que lo reconozca.

18 Según esta STC, uel desarrollo legislativo de un derecho proclamado en abstracto en la Constitución consiste, precisamente, en la determinación de su alcance y límites en relación con otros derechos y con su ejercicio por las demás personas".

19 Este pasaje recuerda a la tesis sostenida por Fernández Rodriguez, T. R., Las leyes orgánicas y el bloque de la constitucionalidad. Civitas. Madrid, 1981, pp. 51 y ss., donde explica el significado y alcance de la reserva de la ley orgánica asimilando su función en relación con la Constitución a la que cumplen los reglamentos ejecutivos con respecto a las leyes. Es decir, servir de "complemento indispensable" de la norma fundamental, ocupándose exclusivamente de aquello que permita que la norma constitucional que contemple un derecho fundamental "pueda funcionar correctamente y alcanzar la operatividad social a la que está constitucionalmente avocada". 
dos en la Sección 1. ${ }^{\mathrm{a}}$ del Capítulo II del Título I, con la excepción del 14, y el segundo (artículo 53.1 CE), a la regulación del ejercicio de los derechos reconocidos en todo el Capítulo II. "Y, si en muchas ocasiones puede haber una coincidencia entre ambos, eso no desmiente-decia el autor citado- la diferenciación apuntada, que requerirá la comprobación caso por caso, lo cual llevará a soluciones distintas pero, en el bien entendido, que a la ley orgánica le corresponderá regular «algo menos" que el ejercicio de los derechos fundamentales ${ }^{20}$.

Con el mismo afán de precisar el ámbito de la reserva de la ley orgánica, otros autores no se han preguntado por el máximo de regulación que le corresponde abordar, sino por el mínimo. Es decir, por la regulación del núcleo central de cada materia, lo cual, en el caso de los derechos fundamentales, vendría a coincidir con el contenido esencial $y$, por eso, sería muy escasa y susceptible de ir acompañada de la remisión o colaboración con la ley ordinaria, incluida la autonómica (STC 137/1986) y de desarrollo directo por el reglamento (STC 77/1985) ${ }^{21}$. La clave para determinar el ámbito reservado y estricto de la ley orgánica podría estar, entonces, en la identificación de los elementos que integran su contenido esencial. El resto de la regulación sobre las condiciones de ejercicio del derecho quedaría abierto a la normación por ley ordinaria que, según resulte de las reglas de distribución competencial, se realizaría por las Cortes Generales o por el correspondiente Parlamento autonómico.

Frente a este planteamiento, el voto particular a la STC 173/1998, sostiene que la ley orgánica no puede limitarse a regular los «aspectos esenciales", al desarrollo directo del derecho en abstracto o en cuanto tal, ya que el contenido esencial de los derechos es siempre indisponible y su definición establecida ex Constitutione sólo puede facilitarla el Tribunal Constitucional. Por otra parte, acusa al fallo de confundir la regulación del ejercicio del derecho a la que se refiere el artículo 53.1 CE con la regulación de la materia sobre la que se proyecta el derecho fundamental. A su juicio, un derecho fundamental sólo puede proyectarse

\footnotetext{
20 DE OTTO, I., ibidem.

21 De la Quadra Salcedo, T., "La ley en la Constitución: leyes orgánicas", REDA n. 24,1980 , pp. 49 y ss., Santamaría Pastor, J. A., Fundamentos..., ob. cit. p. 571. Un supuesto concreto en el que el Tribunal Constitucional ha admitido expresamente esta doctrina es, precisamente, el desarrollo del derecho de asociación. Asi, la STC 67/1985, de 24 de mayo, reconoció que la ley ordinaria podía incidir sobre modalidades o tipos específicos de asociación siempre que se respete a la ley orgánica de desarrollo general de este derecho.
} 
sobre ámbitos (civil, penal, laboral...), pero no sobre materias y, desde luego, sólo puede proyectarse cuando ya está enteramente configurado como derecho (esto es, "desarrollado": artículo 81.1 CE) y cuando se han regulado las condiciones de su ejercicio (artículo $53.1 \mathrm{CE}$ ). En su opinión, el desarrollo de los derechos fundamentales consiste en la concreción de la definición genérica y abstracta con que es reconocido en el correspondiente precepto de la Constitución. Es éste, no la libertad, la que se desarrolla.

En mi opinión, una concepción tan amplia del desarrollo del derecho fundamental supone negar el carácter extraordinario de la reserva de ley orgánica que àntes hemos expuesto. Entender el desarrollo como la configuración acabada de todos los elementos (principales y accesorios) del derecho desnaturaliza por completo la función excepcional que la Constitución confiere a la ley orgánica y la asimila a la labor de detalle que cumplen los reglamentos con respecto a las leyes. Ignora que aunque la ley orgánica se haya considerado el complemento indispensable de la norma constitucional eso no significa que pueda agotar la regulación del derecho pues, a diferencia de los reglamentos, ha de dejar un espacio a la libre configuración, por el legislador ordinario, del ejercicio del derecho sin petrificar mediante una regulación exhaustiva todos los contornos del mismo. De lo contrario, se conseguiría la retención en manos del Estado no sólo de ese suerte de poder constituyente de segundo grado que entrañan las leyes orgánicas, sino de toda la función legislativa para establecer el entero régimen jurídico del derecho de que se trate a costa del sacrificio del ámbito propio del legislador ordinario estatal. Se vulneraría, en definitiva, la reserva de ley orgánica y, como más tarde veremos, se privaría de sentido a las normas del bloque de la constitucionalidad que distribuyen las competencias entre el Estado y las Comunidades Autónomas.

Por eso considero más acertado atender a lo que para cada derecho establezca el precepto constitucional que lo reconozca, ponerlo en conexión con la apertura del 10.2 CE, e interpretar el alcance de la reserva sin perder de vista la dimensión institucional y la relación del derecho con los demás derechos y deberes. En tal sentido, la argumentación de la STC 173/1998 (referida al derecho de asociación) me convence mucho más que la sostenida por los signatarios del voto particular. Con los debidos matices, puede servir para extender sus conclusiones a otros derechos. En efecto, la sentencia citada no se centra en el contenido esencial del derecho sino en "los elementos esenciales de la definición del derechon. Es decir, los relativos a:

- La titularidad del derecho. 
- Las facultades elementales que integran su contenido, tanto en su proyección hacia los poderes públicos como en las relaciones inter privatos.

- Las garantías fundamentales para preservarlos frente a la injerencia de los poderes públicos.

- Los límites en relación con otros derechos y libertades constitucionalmente reconocidos.

Es evidente que la titularidad, el sujeto de los derechos fundamentales, es una cuestión de máxima importancia que, sin embargo, la Constitución no siempre precisa. En efecto, el reconocimiento de los derechos fundamentales que realiza el Título I de la Constitución se concreta en diversos tipos de enunciados en lo que a los sujetos activos de los mismos se refiere. Parece que, en aquellos casos en los que la fórmula empleada, es "Todos", "Toda persona", "Nadie» o, simplemente, el impersonal "Se", hay que interpretar que cualquier persona, y no sólo los españoles o los ciudadanos, son titulares de los mismos ${ }^{22}$. La determinación de tal extremo en cada caso es, sin duda alguna, una tarea que entra en el desarrollo directo del derecho y permite adecuar la disciplina del mismo a las exigencias de la realidad de cada etapa histórica. Por eso, la ley orgánica es la llamada a determinar si, con arreglo al precepto constitucional de que se trate y sin alejarse de los dictados del artículo $10.1 \mathrm{CE}$, los menores, los extranjeros, las personas jurídicas o los grupos gozan de la condición de sujetos activos del derecho en cuestión. Cuando sea un derecho de ejercicio colectivo, como el de reunión o el de asociación, también habrá de fijar cuántas personas individuales han de concurrir a su ejercicio.

La titularidad de los derechos fundamentales por los extranjeros ha sido objeto de controversia debido al juego de remisiones y excep-

22 Asi, los artículos 15, 27, 28, 44 y 45 por ejemplo, utilizan la expresión "Todos"; el 17 habla de "Toda persona"; el 24.1 emplea en plural la misma expresión. Con el mismo alcance, pero en negativo, otros artículos, como el 16.2, el 17.2 y el 25.1 usan el "Nadie». Por su parte, los artículos 20, 21, 22, 33, 34, 37 y 38 acuden al impersonal "Se". Hay también referencias igualmente genéricas, como la del artículo 32, al «..hombre y la mujern.

Sin embargo, otros preceptos constitucionales, algunos de los cuales se encuentran en el Capítulo III del Título I, referido a los principios rectores de política social y económica, limitan el ejercicio de los derechos que regulan a los "españoles" (artículos 11.2, 14, 19, 30, 35 y 47) o a los "ciudadanos" (artículos 23, 41 y 49). Ver CRUz VILLALÓN, P. «Dos cuestiones de titularidad de derechos: los extranjeros; las personas juridicas». R.E.D.C., n. ${ }^{\circ} 35$, mayo-agosto, 1992, pp. 64 y 65. 
ciones que contiene el poco claro artículo $13 \mathrm{CE}^{23}$. En efecto, el apartado 1 del precepto citado comienza afirmando que ulos extranjeros gozarán en España de las libertades públicas que garantiza el presente Título» para, acto y seguido, matizar tan generosa declaración añadiendo uen los términos que establezcan los tratados y la ley". Ahora bien, como ha declarado el Tribunal Constitucional (STC 107/1984, fundamento jurídico $3)$, tal matización solo afecta a la configuración legal de los derechos afectados. Estos siguen siendo derechos constitucionales que corresponden a los extranjeros por propio mandato constitucional como derechos inherentes a la persona (artículo $10.1 \mathrm{CE}$ ) y no resulta posible un tratamiento desigual respecto a ellos en relación con los españoles ${ }^{24}$.

$\mathrm{Si}$, como acabamos de ver, el ordenamiemto restringe en ocasiones la capacidad para ejercitar algunos derechos, en otras sucede justamente lo contrario, pues no hay restricción sino apertura en favor de personas que, por su edad, no han alcanzado la plena capacidad de obrar. El fundamento del reconocimiento a niños y jóvenes no sólo de la titularidad de un importante elenco de derechos sino, lo que es más importante, de una capacidad progresiva para ejercitarlos está, como dice el preámbulo de la Ley Orgánica 1/1996, de 15 de enero, del Menor, de modificacion parcial del Código Civil y de la Ley de Enjuiciamiento Civil, en la preocupacion de dotar a los menores de un adecuado marco de protección basado en un mayor reconocimiento del papel que éstos desempeñan en la sociedad y en la exigencia de un mayor protagonismo de los mismos. El reflejo constitucional de esta concepción se encuentra en el artículo $39.4 \mathrm{CE}$, que se remite a los acuerdos internacionales entre los que cabe referirse a la Convención de los Derechos del Niño, de las Naciones Unidas, de 20 de noviembre de 1989, ratificado por España el 30 de noviembre de 1990.

En la Constitución no existe un precepto análogo al artículo 19.3 de la Ley Fundamental de Bonn que reconozca a las personas jurídicas los mismos derechos fundamentales que a los nacionales, en la medida que, por su propia naturaleza, les sean aplicables. Sin embargo, eso

23 Ver CRUz VilLaLón, P., ob. cit., pp. 63 y ss. La STC 107/84, precisa que: "Existen derechos que corresponden por igual a españoles $y$ extranjeros $y$ cuya regulación ha de ser igual para ambos; existen derechos que no pertenecen en modo alguno a los extranjeros ( los reconocidos en el artículo 23 de la Constitución según dispone en artículo 13.2 y con la salvedad que contiene); existen otros que pertenecerán o no a los extranjeros según lo dispongan los tratados y las leyes, siendo entonces admisible la diferencia de trato con los españoles en cuanto a su ejercicion.

24 CRUz Villalón, P., ob. cit., p. 65. 
no es obstáculo para interpretar que esa regla también rige en nuestro Ordenamiento al estar implícita en los enunciados de diversos preceptos constitucionales, a los que ya nos hemos referido anteriormente, $y$ que en ella están incluidos los simples grupos sociales.

En ese sentido, se ha pronunciado, además, el Tribunal Constitucional que no duda en afirmar que las personas jurídicas pueden ser titulares de derechos fundamentales en todas las hipótesis en que la instrumentación del derecho o la libertad no aparezcan o sean incompatibles con la naturaleza y la especialidad de fines del ente colectivo (STC 137/1985) ${ }^{25}$.

Asimismo, la identificación de las facultades elementales que dan contenido al derecho forman parte de su definición, si bien aquí, cabe distinguir entre las que integran el contenido esencial y las que no tienen ese carácter. Insistimos, de acuerdo con la tesis institucional de los derechos elaborada por Häberle, que incluso el contenido esencial es cambiante y depende de cómo se ejercite el derecho en cuestión, de lo que refleje la normalidad social. Nuevamente, el margen de actuación del legislador orgánico estarán en función de lo que dispongan los correspondientes artículos de la Constitución, de la apertura que ofrezcan. También tendrá en cuenta la estructura del derecho y su eficacia erga omnes, pues la proyección horizontal de los derechos es una nota propia de la mayoría de los mismos, incluidos, como vimos más atrás, los llamados de libertad, en la medida que comportan relaciones con otros sujetos privados titulares, igualmente, de derechos fundamentales.

Las garantías integran la definición de los derechos. Sirven de escudo protector o de mecanismo de reacción frente a posibles interferencias o ataques a los mismos. La tutela de los derechos, o mejor de cada derecho, es indisociable, de su contenido. No obstante, ha de distinguirse la identificación de la garantía concreta de su instrumentación procesal pues, según ha mantenido siempre el Tribunal Constitucional, los procedimientos para hacerlas efectivas ante los órganos jurisdiccionales quedan fuera de la reserva de ley orgánica ${ }^{26}$.

25 La STC 176/95, de 11 de diciembre, ha reconocido que las personas juridicas y los grupos sociales sin personalidad son titulares del derecho al honor.

26 Según la STC 22/1986, fundamento jurídico 4 , ulas normas procesales no son normas de desarrollo del derecho a la tutela judicial, de aquellas a que se refiere el artículo 81 de la $C E$, sino preceptos que regulan los cauces a través de los cuales tal derecho ha de ejercerse. Otra cosa bien distinta es que de los preceptos contenidos en el apartado segundo del mismo artículo 24 nazcan para el legislador e incluso para el intérprete de la Ley determinadas obligaciones...». 
La fijación de los límites en relación con otros derechos constitucionales pone de relieve la interdependencia de unos derechos con respecto a otros y la necesidad de equilibrarlos. La función compatibilizadora que ello impone no se concibe, entonces como una intromisión en los derechos, ni una vulneración de los mismos, sino que es una simple ordenación que se justifica en la necesidad de salvaguardar otros derechos y de impedir un uso abusivo de los mismos. Ese es el papel que se asigna a la reserva de ley orgánica y que se ha de interpretar sin alterar el significado institucional de los derechos afectados. El carácter "fundamental" de esa labor delimitadora justifica el procedimiento excepcional que conlleva la aprobación de las leyes orgánicas pero exige un uso muy estricto de la misma y, correlativamente, que se evite su ejercicio expansivo.

\section{B) Reserva de ley orgánica y distribución de competencias}

Uno de los puntos centrales del debate abierto en torno a la reserva a la ley orgánica es la discusión de si ésta es, por sí misma, un título atributivo de competencias a favor del Estado, ya que sólo las Cortes pueden aprobarlas (artículo $81 \mathrm{CE}$ ), o si la distribución competencial ha de analizarse atendiendo exclusivamente a las normas de reparto establecidas en el Título VIII de la Constitución.

A primera vista, los términos de la discusión pueden resultar faltos de rigor pues, tal y como se ha explicado, y la STC 173/1998 aclara suficientemente, la función de la reserva del artículo 81 CE y la del Título VIII, son distintas y se mueven en planos bien diferenciados. AquéIla, es un prius, un presupuesto de la distribución competencial en la medida que también lo es para el legislador ordinario estatal. Se justifica en la necesidad que el constituyente sintió de que las Cortes completaran su obra concretando, entre otras cosas, el contenido esencial de los derechos fundamentales de manera directa e inmediata. Su traducción formal fue el establecimiento de un procedimiento extraordinario o excepcional para la aprobación de las leyes que cumplieran esa misión especifica de "constituyente permanente». Es decir, que la reserva estaba concebida como una prolongación imprescindible del texto constitucional, una "retención del poder constituyente", $y$, como tal, debía interpretarse de manera muy restrictiva. Sin embargo, como quiera que, sobre todo en los primeros años de vigencia de la Constitución, se tendió a interpretar el dominio de la ley orgánica en un sentido expansivo que podía suponer la atracción hacia el Estado de materias enteras, la reacción lógica, amparada por diversos pronun- 
ciamientos del Tribunal Constitucional, fue negar a la ley orgánica la función delimitadora de las competencias que una aplicación simplista de esa figura pudiera implicar.

Es en ese contexto de riesgo de desnaturalización de la reserva del artículo $81 \mathrm{CE}$ donde se inscriben los recelos autonómicos y se explica que digamos que no es un título competencial estatal autónomo desvinculado de las reglas generales de distribución de competencias. Ha de quedar claro, por tanto, que el rechazo no está referido a la función que tienen atribuida las leyes orgánicas para el desarrollo directo de los derechos fundamentales. Tampoco a la delimitación que operan con respecto a las leyes ordinarias. Se debe, exclusivamente, al temor de que sirvan de cobertura a un ejercicio abusivo y desviado de su finalidad específica. A que se haga un uso extensivo del concepto de desarrollo directo que no sólo reduzca sensiblemente el espacio que pueda ocupar la ley ordinaria estatal sino, también, y sobre todo, la autonómica. Máxime si, de paso, la ley orgánica se adentra en la regulación de los aspectos sectoriales vinculados al ejercicio de los derechos fundamentales en detrimento de las competencias que, conforme al Título VIII y los estatutos de autonomia, correspondan a las Comunidades Autónomas.

Frutos de esos temores han sido:

- La aclaración de que el hecho de que las leyes orgánicas deban ser aprobadas por las Cortes Generales (artículo 81.2 CE) no significa que esté excluida o negada la posibilidad de que el ejercicio de los derechos fundamentales sea regulado por ley de la Comunidad Autónoma en lo que no sea desarrollo directo y estricto de las normas constitucionales que los declaren.

- La advertencia de que las razones que impiden a la ley orgánica apropiarse o invadir el terreno de la ley ordinaria estatal, excepción hecha de las materias conexas y siempre que las identifique, tampoco le permiten adentrarse en el de la ley autonómica, o, por último,

- La afirmación de que la coherencia interna de la Constitución se resentiría si se desvirtuara una atribución especifica cualquiera por lo establecido en una reserva que tiene otra función. $O$, en palabras de la STC 137/86, que "un precepto ordenador del sistema de fuentes en el ordenamiento integral del Estado (artículo 81.1 CE) (no) puede sobreponerse a la norma que, en un plano del todo diverso, busca articular los ámbitos materiales que corresponden a ordenamientos diversos, por más que obviamente unidos", ya que, "...las normas entronizadoras de reservas a determinadas fuentes no son, sólo por ello, atributivas de competencias a un cierto ente (37/1981)". 
Pero la actitud de desconfianza no explica por sí sola que se haya mantenido la discusión acerca de la relación entre ley orgánica y sistema de distribución de competencias. A ello ha contribuido, también, la falta de acuerdo doctrinal al respecto $y$, de manera decisiva, la sucesión de fallos poco claros e, incluso, contradictorios del Tribunal Constitucional. Así lo reconoce la STC 173/1998 cuyo voto particular discrepa de la mayoría en este punto reiterando el consabido argumento: "el artículo 81.1 CE es, de manera previa a la establecida luego en el artículo 149.1 y $3 \mathrm{CE}$, y de modo indirecto, una norma atributiva de competencias en favor del Estado, pues reserva ciertas materias a una forma jurídica -la ley orgánica- que sólo las Cortes Generales pueden elaborar y aprobar.»

En mi opinión, poco importa lo que se diga acerca de la incidencia mediata o inmediata de la reserva sobre la distribución competencial. Lo relevante es qué respuesta se haya dado previamente a la cuestión principal; es decir, qué extensión se da a la repetida reserva. Si, como se ha defendido más arriba, se aboga por una interpretación restrictiva, carece de interés la discusión sobre si el hecho de que las leyes orgánicas incidan indirectamente sobre las competencias autonómicas, les otorga el carácter de título competencial. Si, por el contrario, se sigue una concepción expansiva y maximalista, la reserva puede adquirir la condición de título prevalente sobre cualquier materia que de algún modo afecte a los derechos fundamentales, superponiéndose a las reglas del Título VIII.

La STC 173/1998, sale al paso de este problema y, oportunamente, admite sin ambages que la jurisprudencia constitucional no ha sido rectilínea en el tratamiento de esta cuestión $y$, viéndose en la necesidad de poner remedio a la confusión, formula tres criterios de interpretación fundamentales:

- El ámbito de la reserva de ley orgánica no es coextenso al de las competencias atribuidas al Estado.

- En aplicación de un elemental criterio de interpretación sistemática, el alcance de la reserva de ley orgánica debe cohonestarse con el contenido de los preceptos del llamado bloque de la constitucionalidad que distribuyen las competencias entre el Estado y las Comunidades Autónomas.

- La realización de esa tarea ha llevado a reservar al Estado ex artículo $81.1 \mathrm{CE}$ la regulación de los aspectos esenciales, el desarrollo directo del derecho fundamental considerado en abstracto o «en cuanto tal», en tanto se atribuye la regulación de la "materia" sobre la que 
se proyecta el derecho al legislador ordinario, estatal o autonómico, con competencias sectoriales sobre la misma (SSTC 127/1994, 61/1997 $y$, en relación concretamente con el derecho de asociación, SSTC $67 / 1985$ y $157 / 1992)$.

Ahora bien, tras la formulación de los tres criterios, el Tribunal se ve obligado a matizar que la pauta interpretativa que integran no puede ser aplicada mecánicamente, ya que con suma frecuencia resulta difícil distinguir dónde acaba el desarrollo directo y dónde empieza la regulación del ejercicio. Para vencer esa dificultad, propone atender no sólo al objeto, sino también al contenido, la intensidad e, incluso, la trascendencia de lo regulado. Expresiones que son análogas a las utilizadas por otras sentencias antes citadas, en especial por la STC 132/1989, que habla de la identificación de los elementos esenciales, capitales o decisivos para la configuración del derecho fundamental. En definitiva, la tesis de la sentencia se basa en la naturaleza cuasiconstitucional y en el carácter excepcional de las leyes orgánicas y, en consecuencia, aplica una interpretación estricta y rigurosa de su alcance que impida la subversión del principio democrático que rige el procedimiento ordinario de elaboración de las leyes mediante la alteración artificial del sistema de mayorías.

\section{C) Ley orgánica y artículo 149.1.1. ${ }^{\circ} \mathrm{CE}$}

Las conclusiones que se han extraído del examen de las leyes orgánicas desde el punto de vista de la organización territorial del Estado permiten diferenciar su función de la que tienen atribuida los títulos competenciales que contiene el artículo 149.1 CE. Asi, la ley orgánica desarrolla directa y estrictamente el derecho fundamental de que se trate (artículo 81.1 CE)y, teniéndola en cuenta, otras normas definen las bases a que hayan de ajustarse las Comunidades Autónomas en el ejercicio de sus competencias (artículo 149.1 en sus diferentes subapartados, excepto el $1 .^{\circ}$ ). Por fin, un tercer tipo de normas (artículo 149.1.1. ${ }^{\circ} \mathrm{CE}$ ), regulan las condiciones básicas que garanticen la igualdad de todos los españoles en el ejercicio de los derechos y en el cumplimiento de los deberes constitucionales. Ni la ley orgánica puede extender su acción utilizando como plataforma la competencia estatal sobre las bases y las condiciones básicas ni éstas pueden, tampoco, ensancharse amparándose en el desarrollo de los derechos fundamentales.

Sin entrar ahora en el análisis de la cláusula del artículo 149.1.1. CE a la luz de la última jurisprudencia constitucional, baste, de mo- 
mento, señalar que su fundamento y su finalidad, al igual que la de los demás títulos que recogen los otros 29 subapartados del artículo 149.1 $\mathrm{CE}$ (que en cada materia establecen un cierto grado de homogeneidad), son distintos a los de la reserva de ley orgánica.

Para llegar a esa conclusión ha sido preciso, no obstante, un largo proceso de reflexión y maduración en el que han participado numerosos autores y una, también larga evolución de la jurisprudencia del Tribunal Constitucional que ha culminado, como ya se ha dicho, con las SSTC $61 / 1997$ y $173 / 1998^{27}$.

A mi juicio, a pesar de los términos necesariamente abstractos que emplea la última sentencia citada, tiene el mérito de dar una respuesta satisfactoria a una cuestión difícil como es encontrar pleno sentido y articular coherentemente previsiones constitucionales que se suelen confundir, o considerar simples reiteraciones de otras más generales o, simplemente, se desvirtúan a través de interpretaciones carentes de la sistemática de la argumentación que exhibe el Tribunal en este pronunciamiento. Además, la doctrina que sienta es coherente con la mantenida con respecto a las leyes orgánicas y da continuidad a la fijada en las SSTC 137/1986 y 61/1997.

Frente a ella el voto particular incurre en una simplificación excesiva de la misión que en el texto constitucional se asigna al artículo 149.1.1. ${ }^{\circ} \mathrm{CE}$. Asi, en él se dice que «no es preciso recurrir (a dicho pre-

27 El punto de partida de esa evolución fue la STC de 13 de febrero de 1983 que vino a superponer las nociones de "desarrollo" y «norma básica» para justificar la competencia estatal argumentando la complementariedad de las mismas. Tal proceder fue objeto de un conocido y comentado voto particular suscrito por los Magistrados Arozamena Sierra y Rubio Llorente, según el cual la segunda de las nociones mencionadas tendrian un alcance más limitado que el definido por el artículo $81.1 \mathrm{CE}$ con referencia al derecho fundamental en juego (se trataba de los contemplados en el artículo $27 \mathrm{CE}$ ) y reducirían el ámbito de la reserva a ley orgánica a lo básico. Es decir, dicha reserva no quedaría determinada por lo que exija el «desarrollo" del derecho fundamental, sino por las reglas competenciales del artículo 149.1 CE. Ver la acertada crítica de PemÁn Gavín, J., ob. cit., p. 217. A raíz de la STC 137/1986, se produce un importante giro en la doctrina del Tribunal Constitucional pues, superando el problema de la superposición entre el "desarrollo" y las "normas básicas", deja sentado que la reserva del artículo 81 CE se refiere exclusivamente a las relaciones ley orgánica-ley ordinaria y que las relaciones entre ley estatal-ley autonómica se rigen por las normas del artículo 149 CE. Las SSTC 61/1997 y $137 / 1998$, confirman esta interpretación aclarando que la separación entre ambos tipos de articulación no significa que la ley orgánica, como norma estatal que es, no tenga ninguna clase de incidencia en la delimitación de las competencias autonómicas. 
cepto) para conferir al Estado competencias de homogeneización que, en el campo de los derechos fundamentales, ya le atribuye el artículo 81.1 CE». Es más, se sostiene que «no debe confundirse <contenido primario $>$ de un derecho fundamental (integrado en el desarrollo del mismo: articulo 81.1 CE) con las <condiciones básicas> del ejercicio del derecho (artículo 149.1.1. ${ }^{\circ} \mathrm{CE}$ ).»

Ciertamente, las expresiones utilizadas por la STC 173/1998 para identificar los ámbitos en los que han de actuar las leyes orgánicas y las que apliquen el artículo 149.1.1. ${ }^{\circ}$ CE son similares. Es posible que se presten a la confusión para quien no esté familiarizado con la jurisprudencia constitucional. Otro tanto ocurre con el concepto de "contenido esencial» 0 , incluso, con la definición que ha dado a la garantía institucional. Pero, con independencia de la fortuna de los enunciados, es indiscutible que no impiden hallar la diferencia del significado constitucional de cada una de las figuras y, sobre todo, su distinto fundamento y finalidad. Al contrario, lo esclarecen en la medida que ello es factible ${ }^{28}$.

En mi opinión, (empleando el mismo razonamiento que el propio voto particular esgrime con respecto al concepto de desarrollo directo), queda claramente establecido que las condiciones básicas del ejercicio de un derecho sólo se pueden proyectar sobre derechos previamente definidos y configurados como tales. Tratándose de derechos fundamentales, únicamente cabe regular tal ejercicio cuando la ley orgánica haya determinado los elementos esenciales de la definición del derecho y tal definición se vaya a concretar por el legislador ordinario. Entonces, y no antes, se podrán señalar cuáles de ellos requieren inexcusablemente de una regulación nuclear uniforme que

28 Ver la STC 61/1997, fundamentos jurídicos 7 y 8 , donde el Tribunal explica, por un lado, que la expresión "condiciones básicas" no es sinónima de "legislación básica", "bases" o "normas básicas" y realiza la importante precisión de que "en efecto, no ha atribuido al Estado la fijación de las condiciones básicas para garantizar la igualdad en el ejercicio de los derechos y libertades constitucionales, sino sólo el establecimiento -eso si entero-de aquéllas condiciones básicas que tiendan a garantizar la igualdad." (...) "Dimensión que no es, en rigor, susceptible de desarrollo como si de unas bases se tratara». Asimismo, declara la sentencia citada, las condiciones básicas no equivalen ni se identifican tampoco con el contenido esencial de los derechos (artículo 53.1 CE) que es «una garantía constitucional en favor del individuo, algo a respetar por el legislador en cada caso competente, no para regular; no es, en definitiva, una técnica que permita determinar lo que al Estado o a las Comunidades Autónomas les corresponde. En términos positivos, pues, tanto el legislador estatal de las condiciones básicas, como el autonómico deben respetar el contenido esencial del derecho (...)". 
evite el riesgo inmediato y directo de un ejercicio desigual derivado de la diferente configuración de los mismos que pudiera decidir el legislador autonómico.

En cuanto a la posibilidad de confundir los conceptos de contenido esencial (artículo 53.1 CE), desarrollo directo (artículo 81.1 CE) y contenido primario (posiciones jurídicas fundamentales...) del derecho (artículo 149.1.1. ${ }^{\text {a }} \mathrm{CE}$ ), hay que tener bien presente el distinto ámbito que, conforme a la Constitución, tienen cada uno de ellos. Así, el primero se predica de los derechos reconocidos en el Capítulo II, del Título I. La reserva de ley orgánica para el desarrollo directo sólo afecta a los de la Sección $1{ }^{a}$, de dicho Capítulo y el contenido primario al que se alude para referirse a la aplicación del artículo 149.1.1. ${ }^{\circ} \mathrm{CE}$, abarca a todo el Título I. De ahí que, aunque los términos sean análogos, no se puede extraer la conclusión de que la misión del último precepto citado queda cumplida por la ley orgánica. Se supone que cada uno de los preceptos mencionados no sólo tiene un ámbito propio sino, también, un cometido específico de tal manera que sea posible que, como sucede con el derecho de asociación, concurran los tres ${ }^{29}$.

La secuencia normativa sería, por tanto, la siguiente:

- La ley orgánica desarrolla directa y estrictamente el artículo que reconozca el derecho fundamental, definiendo sus elementos esenciales $y$ respetando el contenido esencial del derecho fundamental.

- La ley ordinaria estatal, en el marco de la definición realizada por la ley orgánica, puede regular el contenido primario, las posiciones juridicas fundamentales, facultades básicas del derecho en tanto sea imprescindible para garantizar la igualdad en su ejercicio.

- La ley ordinaria (estatal o autonómica, según corresponda en función del reparto competencial) regula el ejercicio del derecho en el respectivo ámbito material de competencias ${ }^{30}$.

29 Ver lucas Verdú, P. y lucas Murillo de la Cueva, P., "Artículo 139. Autonomia e igualdad", en Comentarios a la Constitución Española de 1978, T. X (dir., ALzaga VILLAAMIL, O.), Madrid, 1998, pp. 469 a 485.

30 Obviamente, atendiendo a criterios de técnica legislativa, lo razonable sería que las funciones asignadas a la ley orgánica y a la ley ordinaria estatal se abordaran en un único cuerpo normativo que señalara los preceptos orgánicos, los que contengan condiciones básicas, los que constituyan bases, etc. 


\section{RECAPITULACIÓN}

La doctrina y la jurisprudencia constitucionales han ido arrojando luz sobre las zonas de sombra que daban pie a los planteamientos que durante bastante tiempo han mantenido la existencia de una suerte de cláusula general de la igualdad que apoderaba al Estado para ampliar sus competencias en detrimento de las de las Comunidades Autónomas. El paso fundamental para superar esa interpretación ha venido de la mano de las SSTC 61/1997 y 173/1998 mediante las cuales el Tribunal Constitucional ha precisado el alcance de los preceptos que se invocaban con anterioridad para justificar la expansión de las competencias estatales en aras de una igualdad mal entendida. Así, de acuerdo con la jurisprudencia sentada por los pronunciamientos citados, la reserva de ley orgánica se separa del régimen de distribución competencial y es interpretada en un sentido muy estricto en tanto que supone el ejercicio de una función cuasicontituyente y representa una excepción al régimen de mayorías que la Constitución prevé para la aprobación de las leyes por las Cortes. Por consiguiente, ha de ceñirse a las materias que específicamente se le asignan y limitarse a desarrollar o completar la definición constitucional de los elementos esenciales de cada derecho. Desde el punto de vista competencial, esa reserva no puede calificarse como un título en favor del Estado. Es algo previo, como antes se decía, a la misma distribución. Opera como una prolongación de los preceptos constitucionales a los que desarrolla y ha de circunscribirse a esa tarea. La reserva está dispuesta en relación con el legislador ordinario, estatal y autonómico, y no solamente frente a este último. Por eso, se puede decir que no altera en absoluto el régimen ordinario de competencias.

Así, pues, aunque el sistema es complejo también es coherente $y$, en última instancia, armoniza la decidida promoción y defensa de los derechos fundamentales con la organización territorial del Estado. El binomio derechos fundamentales/autonomía política no expresa, por lo tanto, una tensión dialéctica ni un riesgo para los primeros mayor del que pueda esperarse de los demás órganos del Estado. 